\title{
Nominations open for The BMJ Awards 2014
}

\author{
The BMJ Awards 2014 will honour doctors making a difference in the UK. Rebecca Coombes
} invites you to enter and explains what's new this year

\author{
Rebecca Coombes magazine editor, BMJ
}

The BMJ Awards has rapidly become the biggest night of the year for the medical profession in the UK. And 2014 will be no exception, with new categories, an enhanced judging process, and a strong focus on UK medical talent.

Nominations are now open for the awards (www.thebmjawards. com), back for a sixth year with its headline sponsor, the Medical and Dental Defence Union of Scotland (MDDUS).

For 2014, doctor led teams in the UK have the opportunity to enter 13 categories. Cancer care, diabetes, gastroenterology, primary care, and respiratory medicine are just a handful of specialties recognised.

We've also shaken up some of the categories_-introducing, for example, a patient safety team award to mark Don Berwick's recent review of the NHS. But popular awards remain, such as Research Paper of the Year and our surgical award, which each year remembers British doctor Karen Woo, who was killed while delivering healthcare in Afghanistan.

So why enter? Over the years, The awards have honoured international medical luminaries such as Richard Peto and Bernard Lown, but also doctors who are inspirations in their own backyard, such as Jon Cardy, of West Suffolk Hospital emergency department (box).

Trophies have gone to innovations such as the polystyrene foam vaccine boxes repurposed as incubators to keep newborn babies warm, and to a research paper showing the impact that low cost drug tranexamic acid can have on reducing deaths from bleeding. We've seen a team of airborne Scottish doctors honoured, as well as the cardiac surgeons who bravely became the first to publish their mortality data.

For David Cohen, clinical lead for the stroke team at Northwick Park Hospital, crowned Clinical Leadership Team of the Year 2013, the recognition has been "fantastic". "It's no exaggeration to say it was the best night of the year," says Cohen, whose team built and operates the hyperacute stroke unit at the hospital. "It was a fantastic recognition of work that has been going on at Northwick Park for many years. Apart from relatives' thank you notes, there aren't many avenues for recognition of good work in the NHS. So to have the $B M J$ say 'your team is the best' is wonderful. It's great to have that external validation. The entry process wasn't difficult and the rewards of winning are great."

Just under 300 entries were received last year, and the $B M J$ spent weeks sifting them, drawing up a shortlist of candidates who went through to a final round of judging by an expert panel.

This year, for the first time, shortlisted entries will go through peer review, a move designed to make the awards the most rigorous and a true reflection of clinical talent in the UK.

A specially convened senior judging panel will be the final arbiters of who wins a coveted trophy. Also new for 2014 is the inclusion of interviews with finalists in the judging process.

There is also a new opportunity for feedback: teams can sign up for a benchmarking report to find out how their submission compared to those of competing entrants.

The 2014 awards will culminate on 8 May, when the winners will be announced at a gala dinner in central London.

Sara Hedderwick, a consultant in infectious disease in Belfast and deputy chair of the BMA's consultant committee, was a judge for the 2013 awards. "The awards ceremony was full of clinicians doing fantastic work. They were still as enthusiastic about medicine as the day they had started and hadn't become cynical or ground down. It was incredibly uplifting."

"The quality of entries was high and I imagine we could have picked many more winners from the applicants - it was a hard job. What struck me are the clinical outcomes that can be achieved if you find the right team synergy in the health service."

To nominate your team go to thebmjawards.bmj.com to view relevant category criteria and guidelines for entry.

Good luck!

Cite this as: BMJ 2013;347:f6515

๑ BMJ Publishing Group Ltd 2013 


\begin{abstract}
My BMJ Award: Jon Cardy
Jon Cardy, consultant intensivist and clinical director for A\&E at West Suffolk Hospital, won Clinical Leader of the Year at the BMJ Awards 2012.

He led a dramatic transformation in performance over the whole range of national emergency care quality indicators, including hitting the number one spot in England for the 4 hour wait indicator.

"It was very flattering to be recognised for the work I do. Up until then I was a local district general hospital consultant working in the middle of nowhere and I was suddenly projected into the national view, standing in front of hundreds of people in London making a speech. It was a massive team effort and gave us all a morale boost; the department was buzzing afterwards. I was burning the candle at both ends in the hospital and it was bloody hard work but this award shows that if you do something special it does eventually get noticed and talked about." The accolade has led to national speaking invites, such as to a recent junior doctors' gathering, on the bill with NHS clinical director Bruce Keogh: "It's great to have the opportunity to inspire the next generation of doctors," says Cardy.

Cardy returned to the BMJ Awards 2013, this time as a judge: "I read all of the shortlisted submissions and there was some amazing things going on, some really excellent and innovative projects. I was aghast at the standard and diversity of entrants."
\end{abstract}

\title{
BMJ Award categories 2014
}

\section{Cancer team of the year}

For the team who has made measurable improvements in cancer care

Diabetes Team of the Year

This award, sponsored by Boots UK, recognises an innovative project or initiative that has measurably improved care in diabetes

Healthcare Professional Education Team of the Year

A team judged to have made an outstanding innovation in health care professional education and performance improvement

\section{Gastroenterology Team of the Year}

Judges are looking for a team that has delivered an innovative project or initiative that has measurably improved care in gastroenterology

Emergency Medicine Team of the Year

This award recognises the vibrant and rapidly evolving multidisciplinary specialty of emergency medicine

\section{Karen Woo Surgical Team of the Year}

Sponsored by BUPA, and inspired by the exceptional work of the late Karen Woo, this award honours an innovative project or initiative from a UK based surgical team that has measurably improved surgery; submissions from teams involved in relief projects are also welcome

\section{Primary Care Team of the Year}

This award recognises primary care teams who have had a significant impact on the health and well-being of the wider community

Respiratory Medicine Team of the Year

The winners will have measurably improved care in respiratory medicine

\section{The Berwick Patient Safety Team of the Year}

To mark Don Berwick's 2013 review into improving patient safety in the NHS, this award, sponsored by The Health Foundation, goes to a team that can provide evidence of progress against two or more recommendations in Berwick's report

\section{UK Research Paper of the Year}

This award recognises original research that has the potential to contribute significantly to improving health and health care

\section{Clinical Leadership Team of the Year}

Awaiting criteria

Innovation Team of the Year

Awaiting criteria

\section{Nominate your medical inspiration}

The Lifetime Achievement award, sponsored by GlaxoSmithKline, celebrates a doctor-not necessarily near the end of their career-who has made an outstanding contribution to improving health or healthcare in the UK. The winner will be someone whose work has improved outcomes for patients or public health, and whose career has had considerable influence outside as well as within the UK.

We welcome suggestions for nominations for this category at thebmjawards.bmj.com. The winner will be chosen by our panel of judges,

chaired by the BMJs editor in chief, Fiona Godlee. 